\title{
Misrecognition, Marriage, and Derecognition
}

Christopher F. Zurn, Philosophy Department, University of Massachusetts Boston, 100 Morrissey Blvd., Boston, MA , 02125, USA, christopher.zurn@umb.edu Forthcoming in Recognition Theory as Social Research: Investigating the Dynamics of Social Conflict, ed. Shane O’Neill and Nicholas H. Smith (Palgrave Macmillan: 2011)

\section{Introduction}

Contemporary recognition theory has developed powerful tools for understanding a variety of social problems through the lens of misrecognition. ${ }^{i}$ It has, however, paid somewhat less attention to how to conceive of appropriate responses to misrecognition, usually making the tacit assumption that the proper societal response is adequate or proper affirmative recognition. In this paper I argue that, although affirmative recognition is one potential response to misrecognition, it is not the only such response. In particular, I would like to make the case for derecognition in some cases: derecognition, in particular, through the systematic deinstitutionalization or uncoupling of various reinforcing components of social institutions, components whose tight combination in one social institution has led to the misrecognition in the first place. I make the case through the example of recent United States debates over marriage, especially but not only with respect to gay marriage. I argue that the proper response to the misrecognition of sexual minorities embodied in exclusively heterosexual marriage codes is not affirmative recognition of lesbian and gay marriages, but rather the systematic derecognition of legal marriage as currently understood. I also argue that the systematic misrecognition of women that occurs under the contemporary institution of marriage would likewise best be addressed through legal uncoupling of heterogeneous social components embodied in the contemporary 
social institution of marriage. Clearly not all cases of societal misrecognition—and maybe not even the majority of such cases - call for derecognition. In order to make some headway towards understanding legal derecognition and towards distinguishing when such responses are warranted and when not, the paper uses the social institution of marriage as a test case. The next section distinguishes three typical forms of misrecognition and explains the structure of typical affirmative remedies for them. The paper then suggests how marriage generates these three forms of misrecognition (section 3), investigates some of the problems of affirmative recognition remedies (section 4), and then argues for the superiority of strategies of marital derecognition (section 5). It concludes with some thoughts about other social institutions generating misrecognition that might be productively addressed through derecognition rather than affirmative recognition.

\section{Three Forms of Misrecognition and Affirmative Recognition Remedies}

One of the strengths of recognition theory, especially as developed by Axel Honneth, is that it clearly highlights the connection between everyday normative experiences and historical processes of social development. The story is well-known and compelling: when individuals begin to understand their own negative experiences of misrecognition-abuse, disrespect, denigration, and so on — as structurally related to their membership in various social groups, the normative and motivational grounds are laid for engaging in struggles for adequate, appropriate, proper recognition for the members of the group. In normative terms, the negative experiences are the other of justified ideals of proper recognition that are built into everyday patterns of interaction. In highlighting violations of intersubjective expectations, negative experiences also serve to sharpen awareness of justified forms of intersubjectivity and their particular entailments in various situations. Under propitious conditions, individual negative experiences may then also 
furnish the motivational roots of social struggles for recognition. When successful, such struggles move society forward in better realizing the ideals of adequate recognition, ideals implicit in social interactions but not yet fully realized in the society's institutions (Honneth 1995, 2007).

If we turn to considering three typical forms of misrecognition, it is easy to see how proper, affirmative recognition can come to seem the natural remedy for misrecognition. Take first the form of misrecognition that follows from arbitrarily treating the members of some groups differently from others. Prototypically, members of disfavored groups—constituted around sex, class, race, ethnicity, caste, and so on — are arbitrarily or unjustifiably denied the same forms of affirmative recognition that those in favored groups are. This form of misrecognition might be thought of as arising from morally arbitrary social boundaries, and the proper remedy appears straightforward: affirmative recognition of those previously excluded is to be achieved by their inclusion, that is by extending to the excluded the same forms of proper recognition afforded to those of preferred social groups.

A second form of misrecognition occurs where present social institutions insufficiently or defectively realize the norms of recognition implicitly built in to structures of intersubjectivity. For example, Honneth has argued that the contemporary institutions of capitalism, and their resulting patterns of remuneration and distribution, do not consistently reward employees with reward for individual achievement, even though the normative principle of individual achievement and reward is the correct interpretation of esteem-based recognition in contemporary industrialized society (Honneth 2010). Or for another (less contentious) example, consider the standard critique of merely formal equal legal treatment when afforded to individuals under conditions of substantial material inequality. Although the norms of legal 
recognition demand that each is to be treated as an equal and independent autonomous subject, the social institutions of a formalistic legal equality actually undermine the actual realization of equality, furthering rather to perpetuate and deepen the material inequality some already suffer from. Treating indigent and rich criminal defendants equally by allowing them rights to hire their own lawyers is easily seen to be an insufficient realization of respect-based equal recognition. Like the misrecognition of exclusion, the remedy here also seems straightforwardly the promotion of proper, affirmative recognition: social institutions ought to generate the type of recognition consistent with the implicit normative promises of intersubjectivity. In such cases, that usually requires a more arduous and uncertain set of struggles to fundamentally restructure the mechanisms and dynamics of social institutions, all the while however only in light of normative principles that are already understood to be well-justified and agreed-upon throughout the society.

Consider finally a third typical form of misrecognition: namely, that where current social institutions do generate recognition patterns in line with regnant interpretations of normative principles, but where those principles are themselves unjustifiable. Thus social institutions which, say, allocate esteem on the basis of blood descent, or are involved in the torture of prisoners, or promote or condone the corporal punishment and abuse of children all generate types of misrecognition. Yet the misrecognition is plausibly due to their full realization of bad values, rather than to their insufficient realization of proper values. Although the actual difficulties of correcting for this third type of misrecognition are the most imposing of the three-remedy involves not only the systematic restructuring of social institutions but also convincing a significant proportion of the population that the values they embrace are both unjustified and positively deleterious - the natural remedies appear, once again, to be forms of 
affirmative recognition. For, proper recognition will be brought about both through the revaluation of existing values to bring them into line with adequate and appropriate forms of intersubjectivity, and through the subsequent restructuring of social institutions to generate patterns of social recognition in the light of justifiable ideals.

\section{Marital Misrecognition}

In sum, there are at least three main forms that social misrecognition takes-exclusionary boundaries, insufficient value realization, and bad values — and it seems that the natural remedies for each of these forms involve the pursuit of proper affirmative recognition: respectively, inclusion, full value realization, and revaluation followed by social reconstruction. However, considering the case of marriage calls into question the usefulness of affirmative recognition remedies and shows that derecognition is sometimes recommended as the best remedy for social misrecognition.

\section{A. Marriage, Discrimination and Exclusionary Boundaries}

A recent prominent example of struggle against the first form of misrecognitionexclusionary boundaries - is the fight to legalize same-sex marriage throughout the United States, which has moved from a non-issue a mere 15 years ago to now being the focus of much social and political energy and contestation. ${ }^{\text {ii }}$ Marriage laws in the U.S. are largely determined by the individual states, although the federal government passed a law in 1996 that allowed individual states to give no force to same-sex marriages should they be recognized as valid in other states (Defense of Marriage Act 1996). These laws are in continuous flux currently, but the basic landscape can be summed up in a few statistics (accurate as of April 2010): five of the 50 states afford equal legal rights to marry to both heterosexual and same-sex couples; a further 10 states legally recognize an alternative to marriage for same-sex couples, with widely varying 
degrees of rights and protections; 43 states explicitly ban recognition of same-sex marriages and 19 of those also bar any legal structure similar to marriage for same-sex partners; some $30.4 \%$ of the U.S. population currently lives in jurisdictions where same-sex partners may take advantage of either marriage or marriage-like legal relations; another $40 \%$ of the population lives where such structures are explicitly banned, usually by state constitutional amendments passed within the last 10 years.

Popular and media rhetoric often codes these conflicts as 'cultural' politics, but given the real economic impact that, say, the ability to extend heath insurance benefits to a married partner has in the U.S., coding such conflicts as 'merely cultural' is misleading. On the other hand, applying an economistic logic to marriage laws - arguing for instance as though marriage were a scarce and rivalrous resource and so ensuing in zero-sum games whereby the extension of marriage from opposite-sex to same-sex couples would entail a diminishment in the net worth of marriage to opposite-sex couples - is not only facially unpersuasive but also a bit bizarre. It seems clearer to follow recognition theory in saying, rather, that struggles over same-sex marriage center on issues of how some members of society are to be acknowledged; specifically, on moral considerations of what interpersonal relations are to be recognized by society, where such recognition has legal, economic, cultural, and social ramifications. Because it is crucial to my later argument in favor of derecognition rather than affirmative recognition, it is worth paying some attention to some of these multiple ramifications; they reveal marriage to be a complex social institution that interacts across a multiplicity of social domains.

First notice that marriage is, for all citizens, a legal status, one that gives rise to differential rights and responsibilities for those with that status as opposed to those not. Second, notice that getting married is, from the point of view of the law, a voluntary choice that 
individuals make, agreeing to take on some of the special legal responsibilities it imposes in return for the legal benefits it confers. Even an incomplete list of the benefits and capacities marriage confers in the U.S. - a list arising from the complex, tight coupling between the law, marriage, and other social institutions - is significant: spouses can visit one another in the hospital, make important choices for one another such as health care directives, sign some contracts, and make decisions for an incapacitated spouse, marriage can enable an immigrant spouse to reside with the other spouse and to become a citizen, married persons automatically have claims on the proceeds and a say in the disposition of the estate of a deceased spouse and automatic rights of survivorship over real estate and other property, spouses have rights to control most aspects of the lives of the family's children, even when those children are not biologically related to one or both of the parents, and so on and so forth. Marriage also gives rise to significant legal protections for both spouses: they can't be compelled to testify against one another, they are guaranteed at least some stake in the communal assets that they have built up over time should the relationship be dissolved, and they are guaranteed at least a cognizable interest in visitation rights for children after divorce.

There is a substantial set of federal and state economic benefits that are only available to married couples, including the ability to save on taxes through choosing the couple's filing status and through untaxed transfers of wealth, and, of great monetary value, a surviving spouse's ability to collect various social security and pension benefits. ${ }^{\text {iii }}$ We can easily expand the paradigm of unjust discrimination beyond the realm of governmental policy, to include unequal treatment in other social institutions on morally arbitrary grounds. Here we could list economic benefits provided by private employers, but allocated on the basis of legal marital status, such as affordable health insurance, pension benefits, various insurance plans, and so on. We ought also 
attend to all of the manifold social benefits that come from normally reproducing traditional social institutions. The social aspects are the hardest to generalize about, but are perhaps some of the most important in our everyday life. They include the benefits of being at ease with who one is in public, of being accepted by others, of being recognized and esteemed for the difficult but important achievements of a successful committed relationship, of being able to freely speak on behalf of the one other person you know perhaps better than yourself, of being free of the insistent pressures to do things the same way as everyone else, of being free of the barbs of social shame, of being able to express one of the most basic forms of love, and so on. All of these economic and social benefits are, however, either systematically denied to, or harder to achieve for, non-heterosexual couples in life-long partnerships, yet because of no apparently compelling reasons, and many ignominious ones.

At this point it will help to get a bit more precise about the notion of 'social institution' I am employing. ${ }^{\text {iv }}$ As a rough definition, a social institution is a typical pattern of behavior repeated by persons in a society, where the typicality is usually maintained through negative sanctions for deviant performance, and where that pattern can be traced back to a shared lifeworld of cultural meanings and knowledge, social norms and expectations, and stable and concordant personality structures. Social institutions constitute thereby the social 'facts of life' that each of us needs to negotiate through and around in everyday life. Although they are surely products of human behavior and so malleable over time, they face any particular individual as more or less obdurate bits of social reality, social constraints on action with more or less stringent and unpleasant sanctions for non-normal action. Of course, different social institutions are more or less factical and we can compare them across four dimensions. 
There is first the dimension of insistence: namely, the extent to which the normalizing pressures of a social institution drive individuals to conform to it. Criminal law is particularly insistent, marital law less so (as a collection of modifiable default rules), and sartorial norms even less so. Second, homogeneity concerns the range of activities and practices that constitute an acceptable fulfillment of the social institution. So, while marriage is relatively homogeneous across the various state law regimes in the U.S.--for instance, in all states one may marry only one other person at a time - there are important variations - for instance significant regional variations in the perceived acceptability of divorce. Third, marriage is a comparatively complex social institution since it intersects with various dimensions of intimate, sexual, economic, religious, legal, political, communal, and parental institutions. Thus complexity can be thought of as a measure of how many other social institutions, and how many of their various structures and levels, a social institution is imbricated with. The fourth dimension concerns how tightly coupled changes in the social institution are with effects in the various other social institutions, structures, and levels it interacts with. A change in marriage such that, for instance, more than two people could be married simultaneously would have tight causal connections to the economic role of the household. In general, the more insistent, homogeneous, complex, and tightly coupled a social institution is, the more it will appear to actors as an unchangeable social fact of life, one that presents more varied and more stringent social pressures to reproduce that institution in the normal way.

In these terms, we can now see how the first paradigmatic form of misrecognitionmorally arbitrary discrimination - is perpetuated through the contemporary social institution of marriage because it is relatively insistent for adults, comparatively homogenous, particularly complex and particularly tightly coupled with other social institutions, legal and economic, as 
well as social. In the language of recognition theory, marriage as currently structured unjustifiably denies the members of sexual minorities the social conditions necessary to enable them the opportunity to receive the egalitarian respect-based recognition and individualized esteem-based recognition they deserve as equal and autonomous persons. The exclusionary boundaries of contemporary marriage generate misrecognition, and precisely because of the strongly factical character of the social institution.

\section{B. Marriage, Sex Subordination and Insufficient Value Realization}

One of the signal achievements of the $19^{\text {th }}$ and especially $20^{\text {th }}$ centuries is to have acknowledged, at least theoretically, the injustice of sex inequality and to have taken some positive steps to overcome the manifold ways in which it is manifested and reinforced. The question of course is, if this is so, then why is life still disproportionately poor for women in the U.S., why do women earn a fraction of a man's wage for equal work, why are more women destitute than men, why are women so poorly represented in the upper reaches of power and influence, and so on? ${ }^{\mathrm{v}}$ Surely no single social institution, nor any single cultural, legal, political, or social factor can account for the diverse ways in which women are not equally treated in our society. Nevertheless, it is clear that the social institution of marriage has historically been one of - if not the - keystones in the perpetuation of the subordination of women. Surely it is no longer accurate to analyze contemporary marriage as mainly a vehicle for men to trade their property with other patriarchal leaders of families - trading, that is, both women and other material property — even if it once was (Rubin 1975). And it is no longer the case that marriage involves the total forfeiture of the wife's independent legal and social personality to her husband, as it did under the common law doctrines of coverture (Blackstone 1979; Cott 2000; Regan 1999; Vogel 2000). ${ }^{\mathrm{vi}}$ 
Nevertheless, I contend that the social institution of marriage has not been completely purged of its patriarchal elements nor its continuing causal relevance to the subordination of women. To the extent this is true, then marriage effects misrecognition of women in the second prototypical form of insufficient value realization: although the normative infrastructure of contemporary marriage is structured around the ideals of full sex and gender equality, the social institutions of marriage undermine the achievement of such equality and so ought be substantially restructured.

Two reasonably straightforward, yet powerful, examples of sexual subordination through marriage are still in evidence today: asymmetrical vulnerability, and, the marital rape exemption. Susan Okin argues persuasively that women are made asymmetrically vulnerable through the institution of marriage, and that this differential vulnerability with respect to men renders women less capable of exercising autonomy and choice than men, as well as leading to their diminished access to the material, legal, and political resources needed for a decent life (Okin 1989); (see also (Young 2007). Although I can't reproduce her arguments here, I believe they show that the stereotypical sexual division of labor in the household renders women more vulnerable than men by anticipation of marriage, in marriage, and after marriage. What is especially revealing for my purposes is that her argument shows that marriage has profound asymmetrical effects for all women, even those whose lives do not approximate the traditional patterns, precisely because marriage is a complex and insistent social institution. It is relatively homogeneous in terms of the social expectations concerning the division of reproductive labor; fairly insistent in terms of the demand that all women pattern their behavior in expectation of marriage; complexly interwoven with gender, childrearing, economic, and legal institutions, and is quite tightly coupled to those structures even for unmarried women. 
The second example of sex subordination perpetuated through the social institution of marriage involves the continuing legal relevance of one's marital status to one's protection from or non-responsibility for what is known as marital rape or wife rape. Traditionally, marriage has established the boundaries of legitimate sexual activity and expression between two persons. However, what this has meant in practice is that the husband, upon the speaking of the mutual vows, has an unfettered right to the body of his wife for purposes of sex. Following from the doctrine of coverture, an understanding that a husband could not be charged with sexual assault against his wife was codified and judicially recognized in marital exemptions to the very definition of rape. In short, according to the law, it was close to impossible for a husband to rape his wife, on the theory that the wife had consented to all future sexual acts upon taking her vows. Lest we think this is a quaint relic from a long-gone, dusty epoch, it is important to note that 'not until $1984 \ldots$ did a New York appellate court overturn that state's marital rape exemption-then other states followed' (Cott 2000: 211); (see also (Burgess-Jackson 1998; Ryan 1995). By 1993, all 50 states had acknowledged marital rape as a legal crime, though 33 of those states still allow some exceptions from culpability only for spouses, usually on the theory that forced sexual intercourse is somehow less serious or wrong when perpetrated against someone you are married to. Interestingly, five states have extend these marital 'privileges' to cohabiting partners, apparently on the same theory. Thus more than half of American states (mis)recognize participation in the social institution of marriage as a legal lowering of the bar for state protection from rape. Surely these legal changes are a victory, but just as surely, the prosecution rates of husbands for rape lag well behind those for other forms of rape, most probably because ongoing assumptions and presumptions about both coverture, the husband's rights to his wife's sexual body, and sufficient signs of female consent made by legal actors such as judges, juries, 
prosecutors, police officers, and so on. One way of subordinating a group —of stigmatizing them as lesser moral worth than others and so denying them the recognition necessary for equal selfrespect — is to deny its members basic rights of control over their own body, particularly with respect to their sexual activities.

I don't think that these two examples by any means exhaust the variety of mechanisms through which the subordination of women is effected by marriage. But they should be sufficient to establish the claim that the social institution as currently practiced insufficiently realizes the normative ideals of sex equality and thereby systematically generates misrecognition of women, specifically in the form of disrespecting their equal autonomy of denigrating their equal opportunities for esteem-based recognition. Further, these subordinating effects of marriage occur only because the social institution is complexly related to, and tightly coupled with, other social institutions, such as the gender order, the legal order, the division of labor, contemporary economic relations, and sexuality.

\section{Marriage, Normalization, and Bad Values}

The forms of misrecognition treated above, through exclusionary boundaries and insufficient value realization, both involve normative ideals that are supposed to be justifiable, even as those values are deficiently institutionalized. Many however, are not as sanguine about the normative ideals that the contemporary institution of marriage attempts to realize, objecting rather that it institutionalizes all too well certain deleterious values. So, for instance, Iris Marion Young might object that the general account of marriage presupposed here simply occludes the manifest diversity of non-normative forms of intimacy, partnership, family, and reproduction. According to her, there is no good reason to restrict an account of family life only to the lifelong, committed, sexually intimate, monogamous, two-adult couple. And, there are good reasons 
to have a more capacious understanding that does not automatically exclude from view families formed around adults who are not sexually involved, or single-parent families, or extended families involving kith and kin beyond the nuclear family, or communal groups operating as families, and so on. ${ }^{\mathrm{vii}}$ Marriage as currently practiced bundles together a series of legal, political, social, and cultural rights and benefits and restricts those only to dyadic, heterosexual, life-long committed, sexually intimate adults who are not already related. According to Young's argument, then, marriage tends to be oppressive in drawing a border around the concept of the traditional nuclear family, while stigmatizing, penalizing and delegitimating all other forms of family (Young 1997).

Similar types of worry motivates queer arguments against the simple extension of legal marital status to same-sex couples, that is, the affirmative recognition of gay and lesbian marriages. Michael Warner claims that such calls for the 'normalization' of gay and lesbian relationships by fitting them into the traditional mold of heterosexual marriage ignores the manifold ways in which marriage has been shaped around the politics of shame and the social dynamics of stigma, serving especially to ostracize and oppress queer sexual practices and identities. A focus solely only on the legal status of marriage and its attendant economic advantages overlooks the important emotional investments and cultural meanings involved with the American notion of marriage. According to Warner, marriage, at its core, discriminates between licit and illicit sexual practices and pleasures, normalizes even those who have been traditionally demeaned by homophobia, and so sets up a hierarchy of stigma and disgust for those whose sexual practices and pleasures are taken as most queer (Warner 2000). In overlooking the basic distinction between the normal and the pathological at the heart of marriage as a social institution - and the stigmatization that results from this distinction - an 
account that simply tries to extend the traditional, heterosexual, nuclear model of monogamy to homosexual couples risks reducing the available scope of human possibilities for sexual pleasures and intimacies, and risks foreclosing the radical concept of sexual autonomy opened up by queer politics and culture. ${ }^{\text {viii }}$ As Claudia Card points out, too much focus on the traditional option of dyadic, heterosexual, monogamous coupling tends to simply reinscribe the discriminatory distinctions between straight and queer, only this time perhaps narrowly expanding the ambit of 'normal' to include some socially acceptable gay and lesbian practices, while excluding many other practices that can be acceptable modes of self-realization (Card 1996).

The arguments of Young, Warner, and Card persuasively point out the often-unnoticed social complexity of marriage as a social institution. It is not merely a legal status voluntarily assumed by two adults with various legal and economic consequences, but is also causally connected to other aspects of social life: sexuality and sexual expression, gender and its various norms, family and care-taking structures, friendship and partner intimacy, childhood and childrearing, behavioral norms and ideals of public decency, and so on. They then show the tight coupling of these complex layers, such that the one seemingly simple social status of marriage actual bundles together a number of assumptions about typical cultural meanings, norms of behavior, and psychological dispositions. Young's argument focuses in particular on the narrow homogeneity of acceptable forms of family, partnership, care, and sexual relations assumed by marriage; Warner's and Card's on the peculiar insistence of the institution of marriage with respect to policing boundaries around hetero-normative sexuality and styles of life.

In recognitional terms, the normalization of contemporary marriage violates the claim that individuals have to equal and individualized esteem-based recognition for their particular 
traits, abilities and achievements, and thereby impairs individuals' ability to fully realize themselves. In this case, insistent social pressure is brought to bear in order to bring individuals into line with a narrow band of socially accepted meanings, norms and habits where, however, those meanings, norms and habits are not justifiable and socially necessary constraints upon individuals, but reflect merely the traditional patterns of a perceived majority of the society. Notably, the wrong of marital normalization affect not only sexual minorities, but also all those 'normals' who might otherwise opt for non-traditional sexual practices, parenting roles, cohabitation structures, care-relationships, and so on. Concretely, the young queer flamboyantly coming out of the closet in the big city is normalized by marriage in much the same way as the elderly sisters who wish to gain the same legal and economic benefits, and social recognition, for their commitment to cohabitate and care for each other as is easily available to their heterosexually partnered friends. Both are subject to normalizing misrecognition in the light of inappropriately narrow or even regressive values that are furthered by contemporary marital institutions.

\section{Problems in Affirmative Recognition of Marriage}

How should we envision responding to the recognitional wrongs of discrimination, subordination, and normalization carried by marriage? Although we might intuitively prefer affirmative recognition remedies as the natural staring point, I want now to show some of the ways such responses are ineffective in fully remedying the misrecognition, and precisely because marriage is a complex institution that is tightly coupled with other social institutions.

Take first the legalization of gay marriage as the standard affirmative recognition remedies for marital misrecognition via sexuality discrimination. One must say that, given the surprisingly rapid changes in marital law in the U.S. in the light of what seemed possible even 
five years ago, this reform has been surprisingly successful. Nevertheless, simple legal inclusion of gays and lesbians in the institution appear inevitably to require the unjustifiable exclusion of others from the benefits of the institution: the exclusion of two brothers or of two non-sexual friends from the privileges of legally committed partnerships; the exclusion of groups of three persons who wish the same privileges; the exclusion of those who do not wish to be limited to (serially) monogamous sexual relationships; and so on. Because contemporary marriage couples together legal entitlements concerning reciprocal care relations between adults, norms and expectations about sexual intimacy, social structures of child-rearing and care for other less than fully competent persons, personality norms concerning the relation between gender and sexuality, kinship structures, personal finances, and so on-because marriage is a complex institution — simple affirmative inclusion through extension will inevitably involve various kinds of residual exclusions and unwarranted normalizations. This is one of the crucial points of Young's, Card's and Warner's pointed critiques of the homogeneity and insistence of marriage as currently practiced.

Consider, second, a regime of equal pay for equal work between women and men in the economic sphere as an affirmative recognition remedy for the sex subordination that Okin detects in marriage. Such a regime seeks to have the relevant social institutions more fully realize their implicit ideals of sex equality in order to remedy the misrecognition of women. However, if Okin is correct that the problem is not really one of sex-differentiated wage scales in the employment system, but rather a problem caused by the stereotypical gendered division of labor between unpaid carework and paid work in the official economy, then a remedy directed only at the official economy will be woefully insufficient. What is needed is an end to the gender-based division of unpaid and paid labor, and in particular to the structures of the contemporary family 
and legal system that systematically reproduce that division of labor. And this is because marriage is complex and couples together (at least) economic structures of remuneration, the division of reproductive and household labor, the system of childrearing, the gender system, and the legal system. ${ }^{\text {ix }}$

Consider, finally, the simple affirmative recognition remedy to the problem of the marital rape exception. Recall that, de jure, there is no longer such a recognized exception to rape laws in most U.S. jurisdictions. Yet this has not extirpated the fundamental misrecognition. It is carried and reproduced by an interlocking series of cultural assumptions - about the meaning of marriage as a woman's voluntary subjection to her husband, about the availability of women's bodies to men, about the supposed sexualized inversion of explicit denials into unsaid welcome acceptance, and so on — of gender-differentiated norms of behavior, and of persistent structures of sexual socialization consonant with 'rape culture.' In a sense, overturning the bad values inherited from the patriarchal regime of coverture has been largely achieved through the de jure legal overturning of the marital rape exemption — proper affirmative recognition has been the response to the misrecognition - and yet it has proven insufficient because of the complex and tight connections between marriage, the legal system, and other institutional orders.

\section{Marital Derecognition}

If in fact the problems I've indicated with these affirmative recognition strategies arise from the tight coupling of legal marriage to a complex array of other social institutions, then that is where remedy efforts should be focused. A better strategy might begin by foreswearing the attempt to save the institution of marriage as we know it by getting all of its components coordinated and generating proper affirmative recognition. We might then explore ways to disaggregate the diverse components bundled together in the current legal regime, structuring 
new legal institutions where appropriate according to the specific dynamics and intrinsic social principles of the various social institutions involved. ${ }^{\mathrm{x}}$ In general, what we are aiming for is a set of social relations allowing for a fair bit more heterogeneity in terms of accepted practices, meanings and relationships, a set less insistently normalizing to a hegemonic core or paradigm of marriage and the family, and hence uncoupled from many of the traditionally tight linkages between sex, gender, sexuality, sexual practices, religion, economic distributions, legal rights, state welfare provision, community, procreation, and parenting. This is not to suggest that all of these linkages should be severed; far from it. The ties between, for instance, committed care partnerships and the legal enforceability of specific obligations provide important protections for those in such relationships, especially given the asymmetric vulnerability attendant upon the current gendered structure of economic relations. Furthermore, both the enforceability of obligations against parents and protections from overly-intrusive paternalist bureaucracies in child-rearing are important aspects of contemporary marriage, which, if uncoupled from a regime of marital law, would also require the establishment of functional legal equivalents. In contrast, other kinds of linkages effected by the social institution should be deliberately targeted for decoupling: for instance, links between an oppressive system of gender hierarchy and the restriction of marital rights to heterosexuals alone, and marital law ought to be substantially cut (Hunter 1995). Hence there are two different forms of derecognition I'm concerned with. 'Decoupling' derecognition aims to wholly disassociate legal rules and practices covering marriage or marriage-like relationships from other social institutions marriage had been traditionally coupled with. 'Decomplexifying' derecognition, on the other hand, seeks to separate out various components of the single legal regime of contemporary marriage and institutionalize 
different legal regimes to deal with the diverse parts heretofore bundled together in the single status of marriage.

A very brief summary of some of the central decoupling reforms I consider recommended starts with wholly disassociating legal regimes concerning adult relationships and childrearing from religion. ${ }^{\mathrm{xi}}$ Thus, whether we continue with traditional marital law or adopt the reforms I will recommend anon, religious leaders cannot be deputized to carry out state acknowledgement of those relations nor could religious ceremonies make any differences to individuals' legal status, on simple liberal grounds of individual autonomy and reasonable pluralism. Further sexual practices between consenting adults should be structurally decoupled from legal and economic rights, benefits, and burdens. Whatever the traditional role of marriage had been in policing sexual desires and activities, the state has little legitimate interest in interfering with the sexual relations of consenting adults, as long as those are non-harmful, noncoercive, and non-exploitative. Marriage law or its functional equivalents should be decoupled from sexual activities, sexuality, and sexual practices; in general, criminal rape law should be the central focus of the state's policing of sexuality. Sexual practices and sexuality should also be thoroughly decoupled from economic rights and benefits: thus however private companies and state agencies may provide incentive or disincentives for particular family relationships, they should be entirely independent of considerations of sexuality and sexual activity. And as mentioned above, legal and economic structures should also be decoupled from stereotypical sex-roles and gender norms. In general, I suppose that such decoupling reforms would go some distance toward mitigating the misrecognitions of sexual minorities of exclusionary discrimination and of normalization, as well as the misrecognition of women through sex subordination. 
Turning now to decomplexifying reforms, they fall basically into two different sets of consideration: relationships of mutual care voluntarily assumed between adults, and, relationships between parents and children. Traditional marriage encompasses both areas but, as we have seen, in linking them together with gender norms, sexual practices, religion, family law, economic structures, and so on, committed relationships and parent-child relationships have become vehicles for systematic misrecognition. The strategy of decomplexification seeks to treat under separate legal rules those aspects of interpersonal relationships that ought still to be legally structured or coercively enforced, thereby easing the misrecognitions while maintaining the beneficial aspects of the contemporary marital regime.

Marriage provides important benefits, both for individuals and society at large, to the extent to which it fosters and promotes long-term, stable, voluntarily assumed commitment relationships for mutual care and support between adults. For individuals, marital law—like other sets of default rules concerning free contractual relationships between individuals which establish a structure of responsibilities and property dispensations—-seeks to ensure that parties have freely consented to and continue to consent to the structure of the relationship, to clearly delineate the lines of accountability for particular responsibilities, to provide for an orderly and predictable way to end the relationship, and to prevent forms of illegitimate exploitation and abuse, especially those that trade on inequalities of power and threat capacity. From the point of view of society (and states' legitimate interests in societal health), contemporary marriage is causally connected to goods such as increasing the wealth of citizens, reducing crime, increasing the private provision of goods necessary for life and thereby decreasing the state's responsibility for such provision, controlling the health of the population and so having a role in controlling procreation, adequately educating the citizenry, and so forth. Of course, both sets of benefits- 
individual and societal — accrue to marriage because of the character of the relationship between the partners - stable, long-term, committed, relatively encompassing, centered on individualized support of others' needs, concerned with the pre-eminent interests of any children or other dependents, and so on.

A legal system could continue to maintain these goods without the traditional regime of marriage, however, by entirely substituting analogues to the 'reforms known in France as the pacte civil de solidarité (PACS, a "civil solidarity pact" that bestows benefits on households of all kinds, including cohabiting siblings)' (Warner 2000: 85). Here the legal and economic rights and benefits traditionally bundled together by virtue of marriage are bestowed rather upon registering households irrespective of the sexual practices, their biological relations, and the marital status of the adults in the household. They are basically legal partnership commitments to take on personal responsibilities for the care of specific others, where the partners pool financial resources, with preferential treatment of the collective resources through inheritance benefits, and shared decisional authority over collective matters, complemented by various forms of automatic authority to make decisions on behalf of other members in their absence or in the event of their incapacity. Other preferential legal treatment that is afforded to married couples would be extended to the partners: special immigration and emigration rights, various kinds of welfare benefits and social provisions with rights of survivorship, and so on. As well, any preferential treatment by employers of employees that now tracks marital status- health insurance, life insurance, retirement accounts, and so on—would track civil solidarity pact status instead.

Straight away, PACS remedy the problems of sexuality discrimination, since the functional equivalent substituted for marriage makes no distinctions based upon the sexuality or 
sexual practices of those who adopt the status. PACS also address normalization misrecognitions of marriage, since the law no longer attends to the motivations and reasons individuals have for entering into committed partnerships; it is indifferent to the variety of reasons persons have for committing to partnerships, say, for love, sex, social status, religious obligations, loneliness, and so on. So PACS don't discriminate between, say, intimate partnerships (at the center of the modern paradigm of love-based marriage) and mutual care partnerships. But even though they are laudably generic in this way, PACS still provide the goods of a martial regime that are dependent on reciprocal care and trust between individuals, and a reliable legal context for individual planning and decision-making. Civil solidarity pacts, further, do not ignore the increasing proliferation of family types actually evinced in our society. Rather they would disconnect familial responsibilities and benefits from both sexual and biological relations, connecting them instead to adults' reciprocal commitments to living together in heterogeneous household arrangements and to collectively or individually raising and/or caring for persons in that household. It is important to note here, however, that PACS will fail as a solution to some of the misrecognitions of marriage if they are adopted as a parallel regime to traditional marital law. For if that occurs - as has happened in several U.S. states with 'civil unions' for gays and lesbians parallel to marriage for heterosexuals - then those in PACS will be afforded a secondclass status inferior to traditional marriage, and the misrecognitions of sexuality discrimination and normalization will continue, perhaps only somewhat lessened.

One can imagine that civil solidarity pacts will have some beneficial effects with respect to the problems of sex subordination. For instance by separating mutual care partnerships from sexual activity, they may lessen the de facto continuation of the marital rape exemption. But they are surely insufficient insofar as they do not significantly alter the social structuring dynamics of 
sex and gender distinctions, in particular the generative effects for patriarchy of the sex-based division of labor within the family and its typical gender coding pointed out by Okin. Here it seems to me that Nancy Fraser's proposal for social policies promoting a universal caregiver model — where both men and women are equally encouraged to be both wage earners and care givers in opposition to the current gendered division of such labor-is apropos (Fraser 1994). It is crucial here that the moves towards universal caregiver are supported in law, in the policy regimes of the administrative state, and in the remuneration structure adopted by private firms. Again, derecognition is not always a matter of full decoupling — here between marriage, the gendered division of labor, the law, the state, and the economy — but is often a matter of altering the existing couplings through decomplexification.

I have said much less about childrearing in this paper, but it is not only a crucial part of the current marital regime but also the vehicle for the three types of misrecognition I have identified, in so far as such practices are connected to the subordination of women, and, discrimination against and normalization of sexual minorities. Because the moral infrastructure of the parent-child relationship is distinctive - involuntary for the child, significant differences in resources, capacities and raw power between children and their guardians, strong and asymmetrical psychic dependencies, special parental duties for education, loving support, nurture, and promotion of growth and development—it appears that the law and state's preeminent orientation to the welfare of the child must be retained while decomplexifying marriage. Thus parental duties ought to be enforced against responsible but recalcitrant adults except where children's interest would be significantly better served by removing parental discretion over them. However, parental rights need not be restricted to biological parents, but may be extended to non-biological persons who adopt the legal status of parenthood. Here, I 
envision a regime much like contemporary adoption laws, but allowing for a much greater diversity of parental relations, uncoupled from gender norms, sexual relationships, sexuality and, in general, traditional norms giving special status to ideals of the nuclear family. Perhaps this would be best achieved by foreswearing a two-track model and requiring all parents-whether biological or not, whether one or three, whether in a civil solidarity pact or not—to formally take on legal and social parental obligations for children whose birth and care they are biologically or otherwise directly responsible.

Returning, finally, to the paradigmatic forms of misrecognition, the legal regime for childrearing (barely) sketched here will have some impact on sex subordination to the extent to which child care is increasingly carried out according to the universal caregiver model. More importantly, by delinking sexuality, dyadic intimate partnership, biological descent, gender difference, and civic solidarity partnerships from their traditional couplings to childrearing, this proposal would do much to reduce the sexuality discrimination and normalization effects of the contemporary social institution of marriage. We should not forget that much of the legal, social, economic, and educational structures involved with parents and children are either not available to or significantly constrained for non-heterosexual couples with children, even as parental sex, gender, and sexuality has little effect on the health and welfare of children.

\section{Misrecognition Remedies in Other Contexts}

If derecognition is a sensible response to the misrecognitions of marriage, it might also be useful with respect to other social institutions. Rather than a summarizing conclusion, let me sketch a few other social conflict areas where distinctions between these various types of misrecognition remedies might be useful. 
Consider the various relationships possible between organized religion and the state. If, for instance, a government privileges a particular religion over others, then members of disfavored sects will surely raise complaints of misrecognition insofar as that their claims of conscience are officially disrespected. Affirmative recognition here would involve including previously excluded in the state's regime of affirmative recognition of religion, with predictable effects of residual exclusion. A decomplexifying strategy would seek to retain some forms of legal privilege for conscience — say, tax exemptions for all charitable organizations including religious ones-while getting rid of any legal recognition of religion specifically. A wholesale decoupling strategy, by contrast, would retain no rights or privileges for claims of conscience.

Consider next the esteem-based misrecognitions theorists like Honneth point to where the current occupational role system insufficiently institutionalizes the justice principle of merit based on individual achievement or social contribution (Honneth 2003b, 2003a). An affirmative recognition strategy with respect to law would aim to change legal privileges, and perhaps the legal infrastructure of economic systems, in order to generate material patterns of recognition that track society's intuitive judgments about merit. Legal decomplexification might involve attempts to construct new, or influence existing, reward structures that are directly tied to merit, while uncoupling such structures from other social institutions that generate misrecognition, such as gender roles or class structures or geographical differences. Its hard to imagine what form strict decoupling could even take in this area, unless we were to think about the eradication of all legal and administrative couplings to the economy, the division of labor, educational institutions, property laws, and so on.

Consider finally a variegated set of social conflicts over socially disfavored group-based identities, a set of conflicts over race, ethnicity, caste, sex, linguistic culture, national belonging, 
and colonialism that have been central to the multiculturalism literature (Laden and Owen 2007; Shabani 2007). In response to various forms of group-differentiated misrecognition, mainstream multiculturalism has responded with forms of accommodation along the lines of affirmative recognition. Group-specified rights and legal privileges have been sought to bring parity between the legal treatment of majority culture and dominant groups and previously disfavored groups, ranging from educational entitlements, to multi-lingual policies, hate-crimes laws, various forms of affirmative action or positive discrimination, electoral systems of proportional representation, confederalist systems of shared power, and so on. Derecognition in the form of decoupling, in contrast, can be easily summed up in the simplistic slogan Chief Justice John Roberts of the U.S. Supreme Court used in condemning race-based affirmative action of any form: 'The way to stop discrimination on the basis of race is to stop discriminating on the basis of race' (Parents Involved 2007). If the misrecognition is carried more or less exclusively by state and legal structures - for instance, group-based denials of voting rights or denials of welfare benefitssuch a simple response may be sufficient. And even in more complex situations such as colonial exploitation, full-scale decoupling — here complete decolonization together with full political autonomy - may be warranted. However, one of the central insights of the last 30 years of sustained thinking about such issues has been that each of the various axes of group-based discrimination and subordination overlap and interlink with manifold other axes of power asymmetries. Simple decoupling in the face of this social complexity may afford little more than a clean conscience to leaders who wish to simply wash their hands of any group based distinctions, while doing all too little to remedy deeply over-determined forms of discrimination and subordination. For instance, in the realm of political authority, various forms of nationalidentity based devolution and limited autonomy may work better than wholesale decoupling, 
given the internal and external coordination benefits brought by belonging to larger nation-states. The theoretical discourse of 'intersectionality' resulting from this insight is intended to focus on what this paper has labeled the complexity and tight coupling of various social institutions. If in fact many of the group-differentiated misrecognitions are not merely unidimensional, but rather complexly coupled with other social institutions_-including not only other disfavored group categories but also other major structural social institutions - - then remedies must be sought through more subtle and complex forms of decomplexification that seek to overcome the misrecognitions reproduced precisely through the intricate interconnections between social institutions.

In the end, of course, the proof for any of these cases is in the pudding of concrete analyses of the specific configuration of the social institutions, the forms of misrecognition in question, and the potentials inherent in different remedy strategies. A call, then, to further work.

\section{Endnotes}

${ }^{\mathrm{i}}$ I cannot adequately thank all of the people that have contributed to the various incarnations of this paper. At the least, audiences at the 2009 recognition conference at Queen's University Belfast, UMass Boston, and Agnes Scott College deserve special thanks, as do Amy Allen, Joel Anderson, Martino Traxler, and Shane O'Neill and Nick Smith. Although the theoretical formulations here are mine, I am the joint author with Michelle Saunders of the thoughts expressed, and am further indebted to her for whatever understanding I have of their practical entailments. 
${ }^{\text {ii }}$ For the purposes of this chapter, I simply presume that excluding same-sex couples from the benefits of marriage constitutes a form of arbitrary discrimination, that is, a morally unjustifiable exclusion from the institutional recognition structures afforded to other adults. As such, it constitutes a form of institutionalized disrespect and denigration of members of sexual minorities. A (much) longer version of this paper makes good on these claims.

iii The U.S. GAO issued a report in 2004 indicating that there were 1,138 provisions in United States statutes where marital status made a substantive difference to the individuals having it; that is, 1,138 provisions of federal law available only to same-sex couples (Government Accountability Office 2004).

${ }^{\text {iv }}$ This is an extreme summary of a social ontology I develop in a longer version of this paper.

${ }^{v}$ The Institute for Women's Policy Research regularly updates their reports on various comparative indicators for men and women in the several states of the U.S. See their website for publications: http://www.iwpr.org/index.cfm, particularly their •Status of Women in the States• publications. The United Nations maintains an information office under the title Women Watch that has useful national comparative data: see the web portal at http://www.un.org/womenwatch/.

${ }^{\text {vi }}$ Blackstone famously summarizes the doctrine of coverture in Book I, chapter 15 of his Commentaries as $\bullet$ By marriage, the husband and wife are one person in law: that is, the very being or legal existence of the woman is suspended during the marriage, or at least is incorporated and consolidated into that of the husband: under whose wing, protection, and cover, she performs every thing; and is therefore called in our law-French a feme-covert; is said to be covert-baron, or under the protection and influence of her husband, her baron, or lord; and her condition during her marriage is called her coverture. Upon this principle, of an union of person 
in husband and wife, depend almost all the legal rights, duties, and disabilities, that either of them acquire by the marriage• (Blackstone 1979: 430) (spelling modernized).

${ }^{\text {vii }}$ According to a survey of new mothers in American cities, only 17 percent of women with children who are not married live alone with their children. The remaining 83 percent of unmarried women with children live in households with other adults: either with the father of the children, with the father and other adults, or with other adults unrelated to the children. (SigleRushton and McLanahan 2002)

${ }^{\text {viii }}$ Notably, Andrew Sullivan's neo-conservative argument for gay marriage is precisely tailored to take advantage of the insistently normalizing effects and tight coupling of traditional marriage in order to mold queer sexuality into something 'almost normal' (Sullivan 1996).

${ }^{\mathrm{ix}}$ A different affirmative remedy than equal pay for equal work would be remuneration of care work. This presents more involved issues that I can consider here, but I believe similar problems of the interconnections between marriage, care work, the gender system, and the official economy beset it as well, as shown from feminist and recognition theoretic perspectives (Fraser 1994; Rössler 2005).

${ }^{\mathrm{x}} \mathrm{I}$ am not alone in calling for taking apart the contemporary legal structure of marriage as we know it and substituting functionally superior but targeted legal regimes for the different social relations currently bundled together: aside from Card, Warner, and Young mentioned above, see the varying recommendations of (Metz 2010; Sunstein and Thaler 2008; Vanderheiden 1999; West 2007). It should be clear, however, that I am not endorsing the strict libertarian idea of •privatizing marriage whereby the state's only legal cognition of families would be the enforcement of private and idiosyncratic contracts between adult individuals. 
${ }^{x i}$ Much more extensive consideration of these reforms are given in a longer version of this paper, including arguments showing how they better deal with the misrecognitions of marriage than affirmative remedies. 


\section{Works Cited}

Blackstone, William (1979), Commentaries on the Laws of England: A Facsimile of the First Edition of 1765-1769, IV vols. (I; Chicago: University of Chicago Press).

Burgess-Jackson, Keith (1998), 'Wife Rape', Public Affairs Quarterly, 12 (1), 1-22.

Card, Claudia (1996), 'Against Marriage and Motherhood', Hypatia, 11 (3), 1-23.

Cott, Nancy F. (2000), Public Vows: A History of Marriage and the Nation (Cambridge, MA: Harvard University Press).

'Defense of Marriage Act' (1996), Public Law \# 104-199, 110 United States Statutes at Large 2419; 1 U.S.C. $\S 7$ and 28 U.S.C. $§ 1738$ C.

Fraser, Nancy (1994), 'After the Family Wage: A Postindustrial Thought Experiment', Justice Interruptus: Critical Reflections on the 'Postsocialist' Condition (New York: Routledge), 41-66.

Government Accountability Office (2004), 'Defense of Marriage Act: Update to Prior Report', in Government Accountability Office (ed.), (Washington, DC).

Honneth, Axel (1995), The Struggle for Recognition: The Moral Grammar of Social Conflicts, trans. Joel Anderson (Cambridge, MA: Polity Press).

--- (2003a), 'The Point of Recognition: A Rejoinder to the Rejoinder', Redistribution or Recognition? A Political-Philosophical Exchange (New York: Verso), 237-67.

--- (2003b), 'Redistribution as Recognition: A Response to Nancy Fraser', Redistribution or Recognition? A Political-Philosophical Exchange (New York: Verso), 110-97. --- (2007), Disrespect: The Normative Foundations of Critical Theory (Malden, MA: Polity Press). 
--- (2010), 'Work and Recognition: A Redefinition', in Hans-Christoph Schmidt am Busch and Christopher F. Zurn (eds.), The Philosophy of Recognition: Historical and Contemporary Perspectives (Lanham, MD: Lexington Books), 223-39.

Hunter, Nan D. (1995), 'Marriage, Law, and Gender: A Feminist Inquiry', in David S. Caudill and Steven Jay Gold (eds.), Radical Philosophy of Law : Contemporary Challenges to Mainstream Legal Theory and Practice (Atlantic Highlands, NJ: Humanities Press), 22133.

Laden, Anthony Simon and Owen, David (eds.) (2007), Multiculturalism and Political Theory (New York: Cambridge University Press).

Metz, Tamara (2010), Untying the Knot: Marriage, the State, and the Case for their Divorce (Princeton, NJ: Princeton University Press).

Okin, Susan Moller (1989), Justice, Gender, and the Family (New York: Basic Books).

'Parents Involved In Community Schools v. Seattle School District No. 1 et al.' (2007) 551 U.S. Supreme Court Reporter 701.

Regan, Milton C. (1999), Alone Together: Law and the Meanings of Marriage (New York: Oxford University Press).

Rössler, Beate (2005), 'Arbeit, Anerkennung, Emanzipation', Deutsche Zeitschrift für Philosophie.

Rubin, Gayle (1975), 'The Traffic in Women: Notes on the 'Political Economy' of Sex', in Rayna R. Reiter (ed.), Toward an Anthropology of Women (New York: Monthly Review Press), $157-210$.

Ryan, Rebecca M. (1995), 'The Sex Right: A Legal History of the Marital Rape Exemption', Law and Social Inquiry, 20 (4), 941-1001. 
Shabani, Omid A. Payrow (ed.), (2007), Multiculturalism and Law: A Critical Debate (Cardiff: University of Wales Press).

Sigle-Rushton, Wendy and McLanahan, Sara (2002), 'The Living Arrangements of New Unmarried Mothers', (Princeton, NJ: Center for Research on Child Wellbeing).

Sullivan, Andrew (1996), Virtually Normal : An Argument about Homosexuality (New York: Vintage Books).

Sunstein, Cass R. and Thaler, Richard H. (2008), 'Privatizing Marriage', The Monist, 91 (3-4), $377-87$.

Vanderheiden, Steve (1999), 'Why the State Should Stay out of the Wedding Chapel', Public Affairs Quarterly, 13 (2), 175-90.

Vogel, Ursula (2000), 'Private Contract and Public Institution: The Peculiar Case of Marriage', in Maurizio Passerin d'Entrèves and Ursula Vogel (eds.), Public and Private: Legal, Political and Philosophical Perspectives (New York: Routledge), 177-99.

Warner, Michael (2000), The Trouble with Normal: Sex, Politics, and the Ethics of Queer Life (Cambridge, MA: Harvard University Press).

West, Robin (2007), Marriage, Sexuality, and Gender (Boulder, CO: Paradigm Publishers). Young, Iris Marion (1997), 'Reflections on Families in the Age of Murphy Brown: On Justice, Gender, and Sexuality', Intersecting Voices: Dilemmas of Gender, Political Philosophy, and Policy (Princeton, NJ: Princeton University Press), 95-113.

--- (2007), 'Recognition of Love's Labor: Considering Axel Honneth's Feminism', in Bert van den Brink and David Owen (eds.), Recognition and Power: Axel Honneth and the Tradition of Critical Social Theory (New York: Cambridge University Press), 189-212. 